\title{
Dynamic characterization of the Basilica of S. Maria di Collemaggio after the earthquake of 2009 by means of operational modal analysis
}

\author{
D. Galeota ${ }^{1}$, G. Sforza ${ }^{2}$ \& L. Sbaraglia ${ }^{2}$ \\ ${ }^{1}$ DICEAA - Università di L'Aquila, Italy \\ ${ }^{2}$ Essebi s.r.l., Italy
}

\begin{abstract}
The aim of this work was to verify the dynamic behavior of the masonry shell forming the backbone of the Basilica of S. Maria di Collemaggio, in L'Aquila (Italy), and then to compare it with the experimental results related to previous investigations of the ruinous earthquake of April $6^{\text {th }}, 2009$. This is with the intention of having an objective indication, in quantitative terms, with respect to the actual damage suffered by the construction and effectiveness of the provisional measures put in place immediately after the earthquake. Another aspect, not to be underestimated, was to envisage a method of investigation based solely on environmental noise as a source of excitation, and to highlight the advantages and potentiality for the experimental study of dynamic artifacts typologically similar to the one in question. In this case, the operational modal analysis can reasonably be defined as the investigation technique for excellence as the most immediate, expeditious and reliable. Future developments and implementations, based on the concept of configurations with transducers at a fixed location, will provide the highest and most effective contribution to the branch of health engineering.

Keywords: earthquake, modal testing, operational modal analysis, impact hammer, seismic accelerometer, piezoelectric, health engineering, frequency, modal shape, damping.
\end{abstract}




\section{Introduction}

Santa Maria in Collemaggio is one of the most attractive churches in central Italy. Splendid example of Romanesque architecture in Abruzzo, was built at the end of 1200 s on a hill in the city of L'Aquila. Its present shape is the result of many changes, most of which occurred as a result of the strong earthquakes that occurred throughout the centuries. It has, indeed, suffered many insults including the devastating earthquake of 1703: the longitudinal aisles, reconfigured recently, manifested a good behavior, while the entire portion of the transept was the subject of widespread collapse. Recently, prior to the last earthquake, the basilica has undergone a slight repair with the intent to improve its lateral behavior.

The intervention consisted in inserting some reinforced concrete ring beams and injecting cement slurry mortar to improve the mechanical characteristics of the masonry. In this sense, a study of numerical (FEM) and experimental tests (primarily with the impact hammer) allowed to define the dynamic behavior of the basilica. In particular, a finite element analysis was conducted to predict and visualize the shape of the cross-modal response of the artifact before and after the above action, summarized by an experimental dynamic campaign to determine the efficiency of the structural elements in terms of modal parameters induced. The experimental results of dynamic tests also allowed the validation and optimization of numerical models of the structure and provided information on the overall behavior, difficult to predict with the only theoretical approach. In fact, in masonry complex artifacts such as the present, the behavior of the whole depends not only on the mechanical properties of materials, but primarily by the elements of union between the various primary components [1]. The walls have undergone a hardening due to the intervention: for the first mode the frequency moved from $1.25 \mathrm{~Hz}$ to $1.45 \mathrm{~Hz}(+16 \%)$, while for the second mode moved from $1.72 \mathrm{~Hz}$ to $2.12 \mathrm{~Hz}(+19 \%)$ [2]. The displacements at the ends of the walls are not measured, but assumed zero for the constraints imposed by the rigidity of the transept and the main façade. The comparison also between results obtained with different impacts in different locations showed a good overlap, demonstrating the appropriateness of the method. With regard to the facade, the value of the fundamental frequency is little affected by the quote with values that are placed around $4 \mathrm{~Hz}$, independently from the points of excitation and measurement [3].

On April $6^{\text {th }} 2009$, the earthquake that partially destroyed the city of L'Aquila has caused the total collapse of all elevated structures in the transept of the basilica. It is manifested in the collapse of the wall of the triumphal arch, of terminal pillars of the nave, of the vaulted structures and those of coverage, resulting in a pile of rubble inside the box walls, remained broadly intact and complete up to the top portion. To provisional safeguard, waiting for a comprehensive restoration, a series of measures have been put in place with the intention of providing a monolithic behavior of the box walls. Arches were discharged with underpinnings, pillars were rimmed with polyethylene tape, different systems of shackling active transverse and longitudinal bars along the 
nave and in the apse were applied, carbon fiber prepreg tapes were applied to masonry elements, especially at the ends where fractures occurred, trusses to support the apse vaults have been put in place.
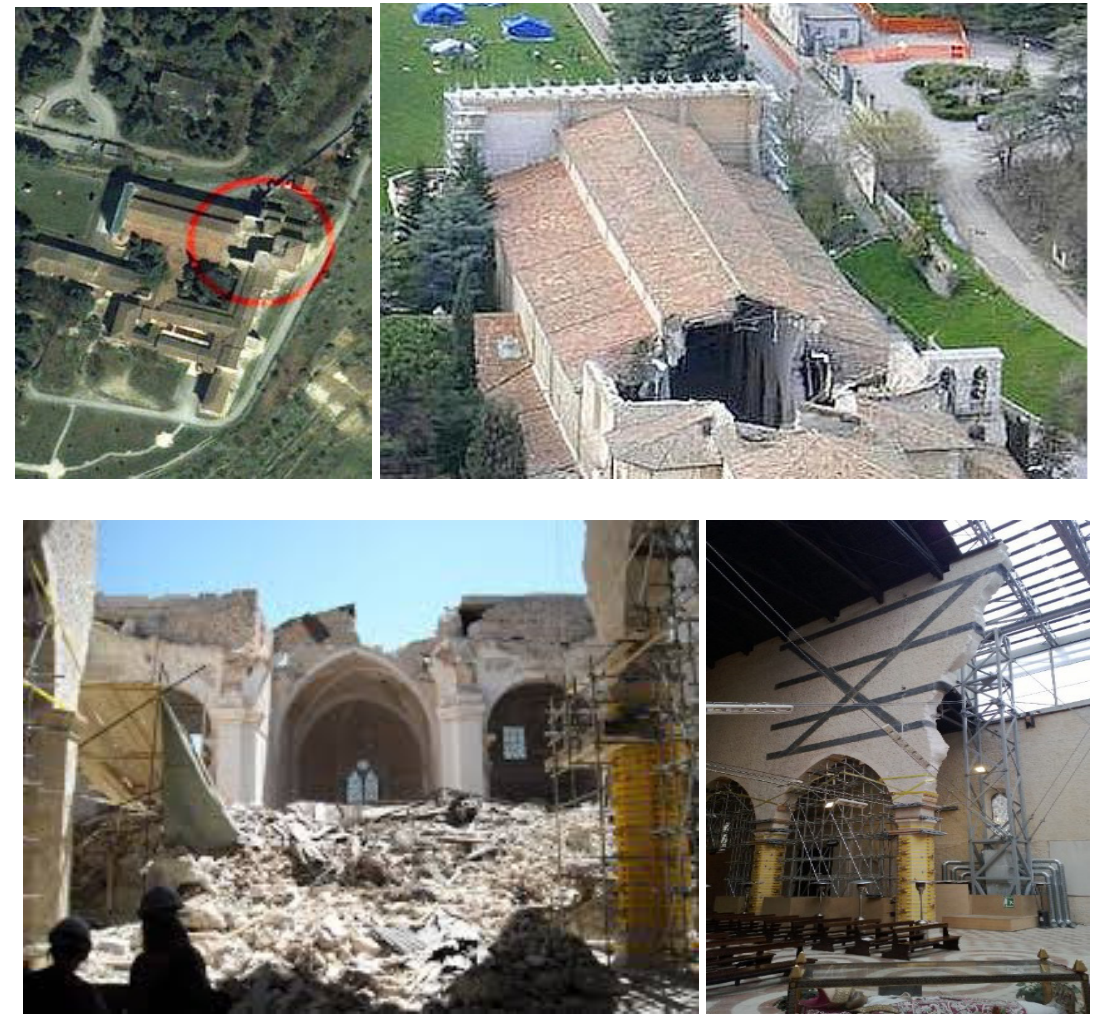

Figure 1: Earthquake effects.

\section{Description of intervention}

Simultaneously with other surveys based on long-term wireless monitoring instrumentation aimed at identifying effects caused by possible earthquakes [4], the entire basilica was subjected to a dynamic analysis in operating conditions [5] with the objective of achieving a representation from the dynamic point of view, i.e. in terms of natural frequencies, damping factors and modal shapes. For this purpose seismic low noise, low frequency accelerometers and high dynamic data acquisition systems were employed. Also an experimental investigation by means of the impact instrumented hammer (classical modal analysis) was conducted, in order to have a comparison with the results obtained with the previous method. The experimental dynamic analysis has been subdivided into phases for the control of various structural portions of the artifact. 

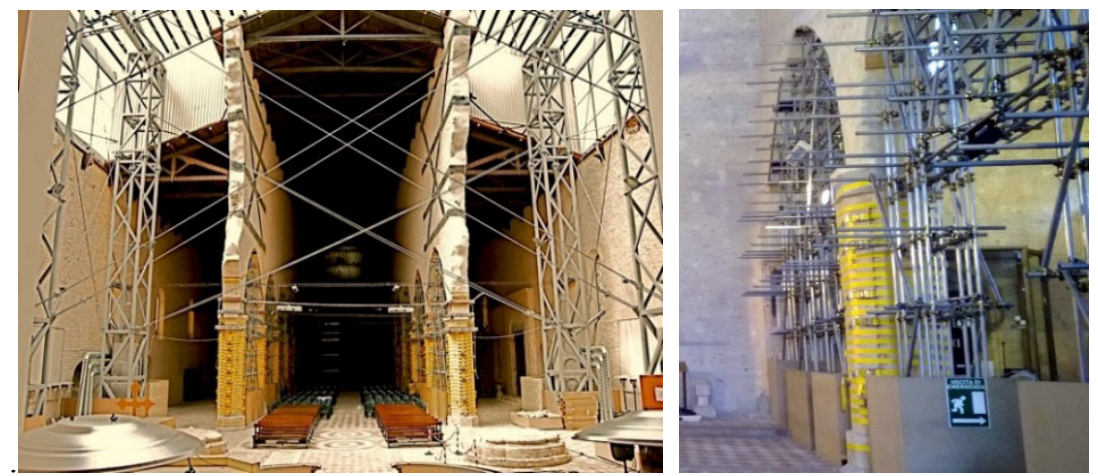

Figure 2: Provisional measures.

In total, 101 measurement points for operational modal testing and 17 measurements points for impact testing were implemented. The experimental tests were performed on different days and data have been related by means of common reference points. For each channel, measures have been carried out with a $200 \mathrm{~Hz}$ sampling frequency, with appropriate analog anti-aliasing filter and consequent bandwidth of $100 \mathrm{~Hz}$.

Referring to the operational steps, the accelerometers were installed separately, for each phase, on structures from time to time under investigation (substructures). For each of them the arrangement has been driven by considerations about the visually observed conditions of damage and about the conceivable and expected modal shapes. For the impact testing two measurement runs were conducted to cover all points planned. The accelerometers were placed in both mono-axial and bi-axial configuration.

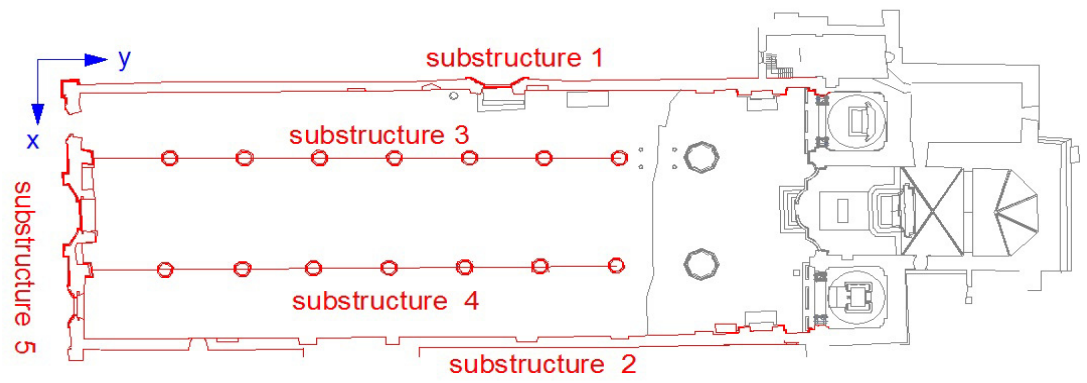

Figure 3: Surveyed substructures.

\section{Measurement apparatus}

The measurement chain is made up by an array of accelerometric transducers connected via signal cables to a dynamic acquisition system. In order to reduce 
the development of the cables, two data acquisition systems, 8 channels each, synchronized on GPS absolute time, have made use of [6].

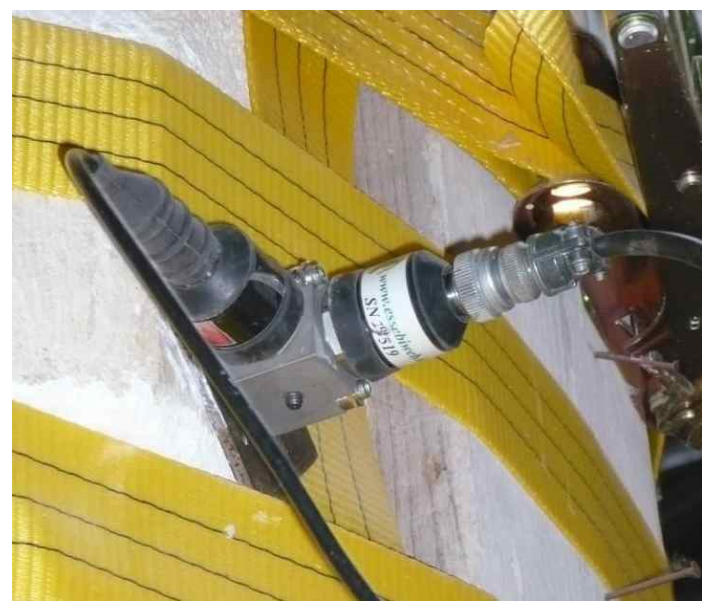

Figure 4: IEPE seismic accelerometer settled on a pillar.

IEPE seismic type accelerometers (high-sensitivity, low noise and capable of sampling at low frequencies) have been utilized: PCB 393A03 (sensitivity $1 \mathrm{~V} / \mathrm{g}$, range \pm 5 g resolution $10 \mu \mathrm{g}$ rms, minimum measurable frequency of $0.2 \mathrm{~Hz} \pm 3$ $\mathrm{dB}$ ) and PCB393B12 (sensitivity $10 \mathrm{~V} / \mathrm{g}$, range $\pm 1 \mathrm{~g}$ resolution $8 \mu \mathrm{g} \mathrm{rms}$, minimum measurable frequency of $0.05 \mathrm{~Hz} \pm 3 \mathrm{~dB}$ ). The characteristics of the PCB 086D20 instrumented impact hammer are the following: sensitivity $0,23 \mathrm{mV} / \mathrm{N}$, full scale $22240 \mathrm{~N}$, resonance frequency $\geq 12 \mathrm{kHz}$. The synchronization of two or more acquisition systems depicts an optimum solution when it is necessary to have many lines of data acquisition simultaneous sampling, with reference to sensors which are very distant between them. Using a single acquisition system would be needed long cables with consequent loss of quality in the signal and difficulty of installation. With the solution applied in this work, however, each of the two systems has been linked to sensors placed on limited portions of the structure via length short cables ( $25 \mathrm{~m} \mathrm{max}$ ).

The first system consists of a PCB Piezotronics mod. 483C05 power supply and signal conditioner for ICP accelerometers combined with an IMC mod. CS7800-1 acquisition system voltage signals (8-channel with simultaneous sampling from 0.1 to $50 \mathrm{k} \mathrm{Hz}$ per channel, A/D 24-bit internal converter, analog low/high/band and anti-aliasing $10-50 \mathrm{k} \mathrm{Hz}$ filters, electrical noise on the entire band less than $5 \mathrm{nV} \mathrm{rms}$ ). The spectrum analyzer is equipped with a DSP able to allow processing (for example, the FFT) in real time, with immediate display of the results of the signal processing. A Garmin GPS antenna and a laptop with Pentium processor family connected via ethernet complete the measurement chain.

The other system is even more compact, manageable with blue-tooth connection by means of a handheld computer and powered with a rechargeable 
battery having autonomy of approx. $2.5 \mathrm{~h}$. It consists of a LMS SCADAS Mobile SCR011 slot module with the V8-E eight channels for voltage and IEPE signals. The V8-E system allows up to $204.8 \mathrm{kHz}$ sampling with A/D conversion to 24 bit. The dynamic range of $150 \mathrm{~dB}$ SFR eliminates the need of having to resort to the choice of the measuring range (adjustable from a maximum of $\pm 10 \mathrm{~V}$ at a minimum $\pm 316 \mathrm{mV}$ ). To facilitate the communication and the synchronization with the other acquisition system, even in this case a GPS antenna has been provided.

In addition to the management field programs of individual acquisition systems, with regard to the extraction of mode shapes, the software LMS Test.Lab (Operational Modal Analysis and Impact Testing) was used.

\section{Experimental results}

For extracting modal parameters has been used the LMS PolyMAX algorithm that is a further polyreference evolution of the least-squares complex frequencydomain (LSCF) estimation method, based on a so-called right matrix-fraction model. In this approach, also the participation factors are available when constructing the stabilization diagram [7]. The main benefits of the polyreference method are the facts that the singular value decomposition (SVD) step to decompose the residues can be avoided and that closely spaced poles can be separated [8]. Here below the most significant mode shapes with relative modal parameters are listed for each substructure investigated. The substructure 4 was divided into two portions: the first more limited close to the entrance area, the second towards the transept.

For the substructure 2 also the second and the third mode are represented. For comparison, also the first two modes obtained with the impact testing relative to the first three substructures taken together are represented.
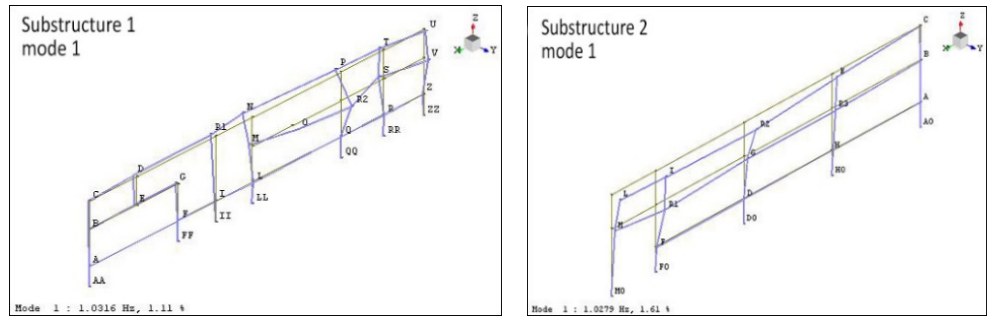

Figure 5: $\quad$ First mode shapes for substructures 1 and 2.

For the substructure 4, it was conducted a double analysis which allowed to identify a behavior that differs along the longitudinal development: for the most of the development, towards the transept, the value of the frequency of the first mode is aligned with that of the other substructures, it almost double nearly the confluence with the main facade, demonstrating a greater stiffness determined by the constraint with it. 

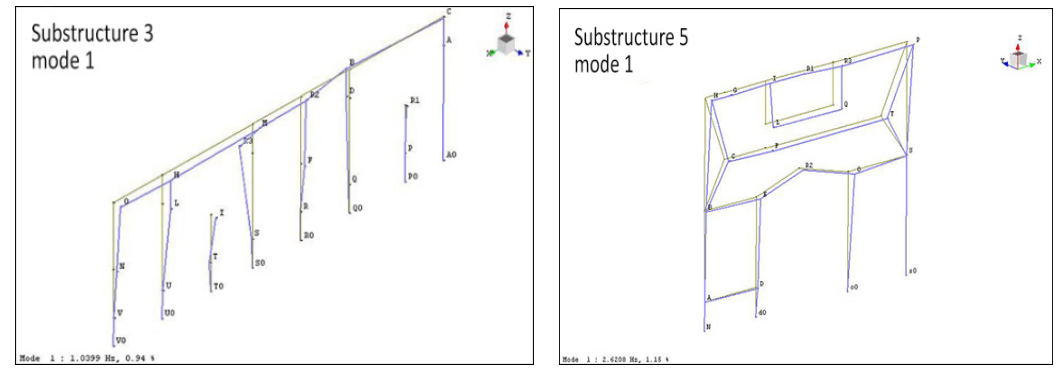

Figure 6: First mode shapes for substructures 3 and 5.

The substructure 5 shows the main façade characterized by higher frequencies than the other four substructures. This is due to greater rigidity in part constitutive and in part favorite to persistent constraint conditions with males orthogonal to it. The façade still shows a significant loosening, much more than what has been reported for the other substructures, compared to what can be deduced from the investigation prior to the earthquake.

Not surprisingly, the façade is found placed almost perpendicular to the direction of seismic wave front, undergoing an oscillatory motion out of the plane that has resulted in plasticization and brittle failures more or less widely.
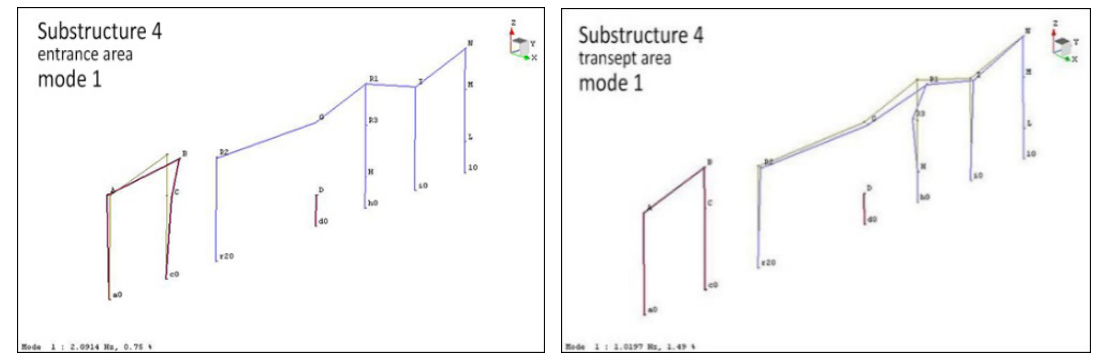

Figure 7: $\quad$ First mode shapes for substructure 4.
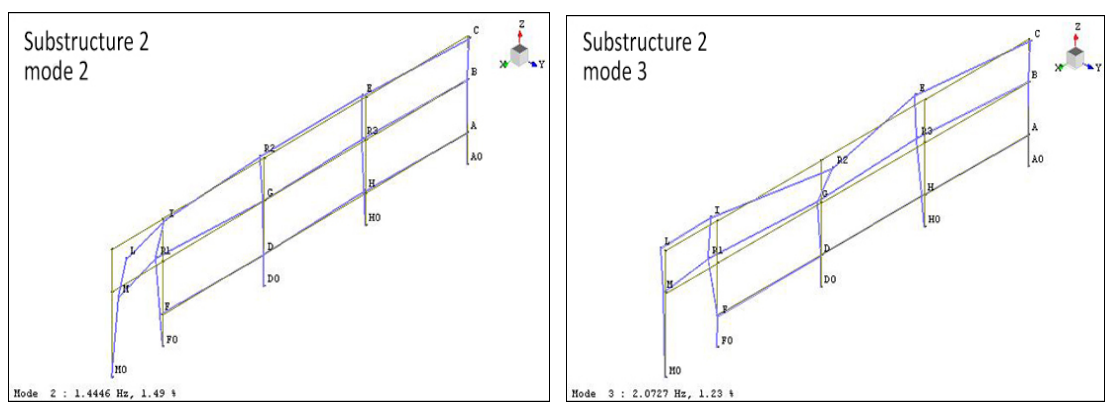

Figure 8: $\quad$ Second and third mode shapes for substructure 2. 
For the first three substructures it was performed a subsequent analysis, by reference solely to the transducers positioned along the top of the walls: this in order to identify secondary modes, attributable to solutions of continuity in the structures, probably caused by elements of longitudinal fracture or by restraints placed along the vertical development. The good correspondence of the results provides an effective indication about a monolithic behavior of the walls. For the same three substructures it was also made an impulsive modal analysis, with an instrumented hammer having the same characteristics as the one used in the previous analysis performed by the University of L'Aquila. Albeit with greater operating difficulty due to a method which is not suitable for large masonry structures, the results were comparable with those of operational modal analysis. Only the damping resulted higher, often more than double. This is inherent in the type of analysis: a localized impact excitation, although of considerable intensity, tends to fade much more quickly as the medium is inhomogeneous and has discontinuities. The increase of the applied force then does not guarantee a uniformity of propagation of the vibratory phenomenon with the consequence of having portions, sometimes of considerable length, not at all concerned.
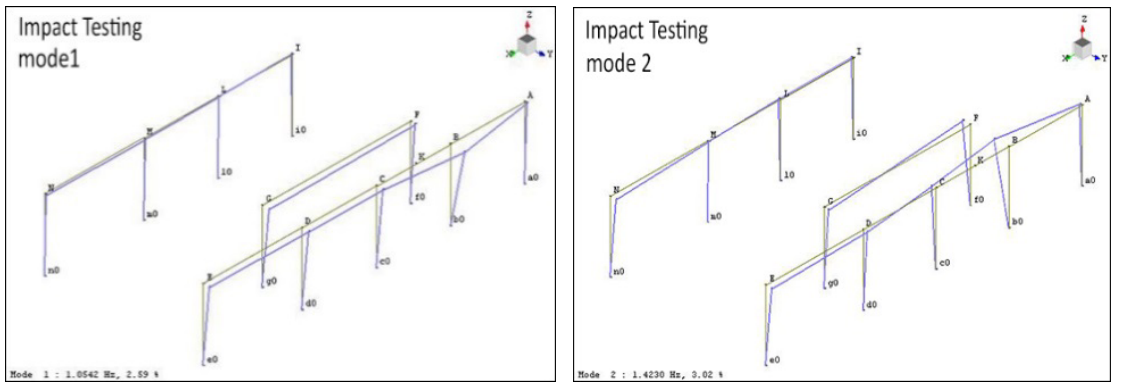

Figure 9: First and second mode shape obtained with the impact testing.

For structures from 1 to 4 , the surveys, with transducers widely distributed on the walls, led to the determination of a flexural first mode between 1.02 and 1.04 $\mathrm{Hz}$, with damping of the order of $1 \%$. For higher modes, although the welldefined forms, there are also significant differences between the various substructures, especially in the values of the second frequency. With reference to previous surveys, there is a reduction of the stiffness varying from $20 \%$ to $30 \%$, depending on it refers to before or after the structural interventions made around the year 2000 .

In addition to the direct method, it was made a comparison on the basis of the index of modal correlation. The Modal Assurance Criterion (MAC) is a measure of the square of the cosine of the angle between two vectors. The MAC calculated for a pair constituted by two vectors corresponding respectively to an analytical mode and to an experimental mode provides an indication of the degree of correlation between the two mode shapes [9]. 
Table 1: Frequency ad damping for each investigated modes.

\begin{tabular}{|c|c|c|c|c|c|c|c|c|c|c|c|c|}
\hline & \multicolumn{2}{|c|}{$\begin{array}{l}\text { Substr. } 1 \\
\text { Holy Door } \\
\text { wall }\end{array}$} & \multicolumn{2}{|c|}{$\begin{array}{c}\text { Substr. } 2 \\
\text { East } \\
\text { external } \\
\text { wall }\end{array}$} & \multicolumn{2}{|c|}{$\begin{array}{c}\text { Substr. } 3 \\
\text { West } \\
\text { colonnade }\end{array}$} & \multicolumn{2}{|c|}{$\begin{array}{l}\text { Substr. } 4 \\
\text { Transept } \\
\text { side }\end{array}$} & \multicolumn{2}{|c|}{$\begin{array}{l}\text { Substr. } 5 \\
\text { Facade }\end{array}$} & \multicolumn{2}{|c|}{$\begin{array}{c}\text { Impact Test } \\
\text { Global }\end{array}$} \\
\hline & $\begin{array}{c}f \\
(H z)\end{array}$ & $\begin{array}{l}\zeta \\
(\%)\end{array}$ & $\begin{array}{c}F \\
(H z)\end{array}$ & $\begin{array}{l}\zeta \\
(\%)\end{array}$ & $\begin{array}{c}f \\
(H z)\end{array}$ & $\begin{array}{l}\zeta \\
(\%)\end{array}$ & $\begin{array}{c}F \\
(H z)\end{array}$ & $\begin{array}{l}\zeta \\
(\%)\end{array}$ & $\begin{array}{c}f \\
(H z)\end{array}$ & $\begin{array}{l}\zeta \\
(\%)\end{array}$ & $\begin{array}{c}F \\
(H z)\end{array}$ & $\begin{array}{l}\zeta \\
(\%)\end{array}$ \\
\hline Mode 1 & 1.03 & 1.11 & 1.03 & 1.61 & 1.04 & 0.94 & 1.02 & 1.49 & 2.62 & 1.15 & 1.05 & 2.59 \\
\hline Mode 2 & 1.07 & 0.73 & 1.44 & 1.49 & 1.09 & 1.29 & 2.07 & 1.14 & 4.28 & 0.47 & 1.42 & 3.02 \\
\hline Mode 3 & 2.08 & 1.34 & 2.07 & 1.23 & 1.98 & 0.47 & 2.77 & 0.70 & 5.79 & 1.25 & 2.10 & 1.63 \\
\hline Mode 4 & 2.58 & 0.42 & 2.29 & 1.00 & 2.65 & 0.75 & 3.61 & 0.44 & 7.50 & 0.32 & 2.66 & 3.32 \\
\hline Mode 5 & 3.07 & 0.67 & 4.71 & 0.91 & 2.76 & 0.64 & 4.70 & 0.39 & 8.30 & 1.10 & 3.36 & 2.06 \\
\hline
\end{tabular}

\section{Conclusions}

The experimental modal analysis has allowed to determine the characteristic modes and the dynamic parameters of the substructures investigated, which identify the portions of the box walls remained intact following the earthquake of April 2009, albeit with significant provisional measures. For reasons of practical accessibility with lifting equipment available, it was not possible to complete the work in relation to the remaining portion concerning the transept and the apse area, the most damaged, and therefore not very meaningful for the purposes of the dynamic behavior.

Beyond the results obtained, extremely useful for the mechanical identification of investigated portions, we want to emphasize the importance of having proposed and applied a method which is the most suitable, expeditious and effective for this type of manufactured masonry. Exploiting, in fact, the only environmental white noise (i.e. wind and traffic), the stresses are considerable and spatially distributed in a uniform manner to affect the entire artifact in the whole of time in which the analysis takes place that must be sufficiently long. In addition to this we should remember the distinction of having used a measuring chain of excellent performance characteristics: high dynamic acquisition systems, able to appreciate low signal without going off the scale to the occurrence of significant events, combined with seismic accelerometer transducers of great value, with very low spectral noise and able to work at very low frequency. The acquired data have been processed with a powerful, versatile and sophisticated software algorithm based on the extraction of mode shapes, operating both in the time domain and in the frequency one. 


\section{References}

[1] Antonacci E., Beolchini G.C., Di Fabio F., \& Gattulli, V. 2001a Retrofitting effects on the dynamic behaviour of $S$. Maria di Collemaggio, Computational Methods and Experimental Measurements, CMEM 2001, Proc. intern. congress, Alicante, 6-8 June 2001, Southampton: WIT Press.

[2] Antonacci E., Beolchini G.C., Di Fabio F., \& Gattulli, V. The dynamic behaviour of the Basilica S. Maria di Collemaggio, Proc. of 2 nd Int. Congress on Studies in Ancient Structures, SAS2001; Istanbul, 9-13 July 2001.

[3] Antonacci, E., \& Beolchini, G.C., The dynamic behaviour of the facade of the Basilica S. Maria di Collemaggio IV Edition of the International Seminar Structural Analysis of Historical Constructions, Padova 10-13 November 2004.

[4] Antonacci E., A. Ceci, A. Colarieti, V. Gattulli, F. Graziosi, M. Lepidi, \& F. Potenza, Dynamic testing and health monitoring via wireless sensor networks in the post-earthquake assessment of structural condition at L'Aquila. 8th European Conference on Structural Dynamics, Eurodyn11, Leuven, Belgium, 2011.

[5] Peeters B., Sforza G., Sbaraglia L., \& Germano F. Efficient operational modal testing and analysis for design verification and restoration baseline assessment: Italian case. EVACES 2011, Varenna (LC), Ottobre 2011.

[6] Doebelin E.O. Measurement Systems Fourth Edition - 1990 - McGraw Hill.

[7] Heylen W., Lammens S., \& Sas P. Modal Analysis Theory and Testing Katholieke Universiteit Leuven, Heverlee (Belgium), 2003.

[8] Zhag L., Brincker R., \& Andersen P. An overview of operational modal analysis: Major development and issues. Proc. From the $2^{\text {nd }}$ International Operational Modal Analysis Conference, Copenhagen, Denmark 2011.

[9] Ewins D. J. "Modal Testing: Theory practice and applications, Research Studies Press LTD, Baldock, Hertfordshire, England $2^{\text {nd }}$ Edition -2000. 